\title{
Intravenous drug abuse and the accident and emergency department
}

\author{
M. G. DUNLOP AND D. J. STEEDMAN \\ Department of Accident and Emergency Medicine, Royal Infirmary, Edinburgh, \\ Scotland
}

\section{SUMMARY}

A 4-month prospective study of intravenous drug abusers attending an accident and emergency department was performed. A total of 92 patients presented with 104 new complaints. Seventy-eight per cent of patients were under 30 years of age and $28 \%$ were female. The primary reason for attendance was related to trauma in $30 \%$ of attendances, accidental or deliberate overdose in $26 \%$ and as a result of infection in $26 \%$. A total of $37 \%$ of all attendances resulted in admission and two patients died in the department. Fifty-four patients $(58 \%)$ had radioimmunoassay performed for hepatitis $\mathrm{B}$ markers and there was evidence of past or ongoing infection in $87 \%$ of these patients. Only three patients $(5 \cdot 6 \%)$ were $\mathrm{HBsAg}$ positive at the time of presentation.

Accident and emergency staff should be made aware of the pattern of attendance of intravenous drug abusers and the particular problems they present.

\section{INTRODUCTION}

The recent increase in parenteral drug abuse in the United Kingdom has been paralleled by a rise in the number of patients who attend the accident and emergency department as a consequence of intravenous drug abuse or in whom the habit is noted coincidentally (McGowan et al., 1984). Despite this trend there has been no prospective study to determine the pattern of presentation and particular problems related to the management of these patients. This study aimed to provide basic information related to the attendance of intravenous drug abusers at a teaching hospital accident and emergency department.

Correspondence: Dr D. F. Steedman, Department of Accident and Emergency Medicine, Royal Infirmary, Lauriston Place, Edinburgh, EH3 9YW, Scotland 
A prospective study was performed over a 4-month period (1 May-31 August 1984) of patients who were noted to be intravenous drug abusers presenting to the Accident and Emergency Department at Edinburgh Royal Infirmary. The following information was obtained for each patient: age; sex; presenting problem; and disposal. Hepatitis B status $\stackrel{\oplus}{+}$ was determined in those patients in whom there was a specific indication, such as the management of an open wound or soft tissue abscess, and in those patients who would $\frac{\overline{\bar{N}}}{\mathrm{~F}}$. require further invasive investigation. Status was ascertained by radioimmunoassay for $\mathrm{HBsAg}$, anti-HBs, anti-HBc, anti-HBcIgM and where $\mathrm{HBsAg}$ was positive $\mathrm{HBeAg}$ ando anti-HBe were also assayed.

\section{RESULTS}

\section{Number of patients}

A total of 92 patients attended with 104 new complaints. The distribution of attendances over the 4-month period is illustrated in Fig. 1.

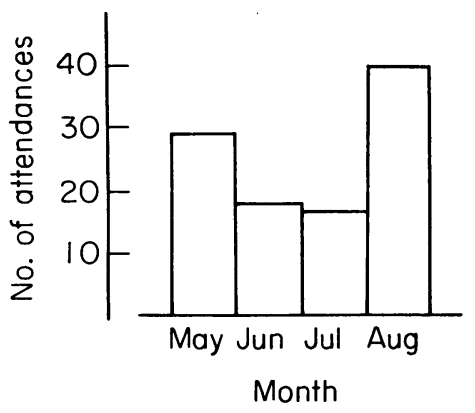

Fig. 1 Distribution of attendance.

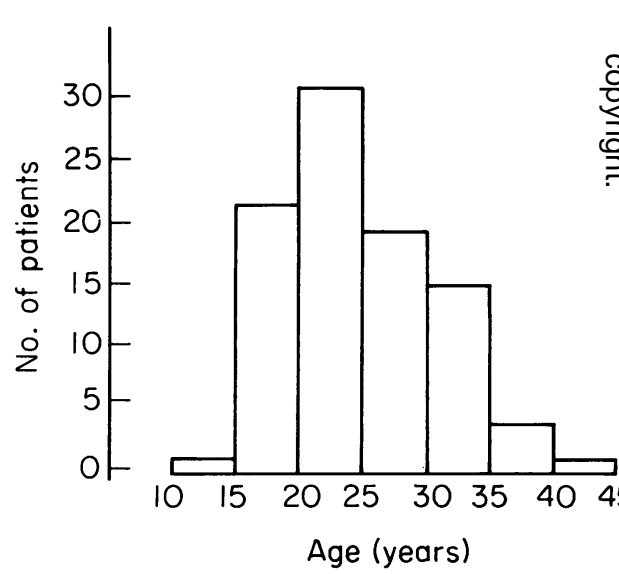

Fig. 2 Age distribution.

\section{Age and sex}

The age distribution is shown in Fig. 2. A total of $78 \%$ of all patients were under $30^{\circ}$ years of age at the time of presentation and $28 \%$ of all patients were female.

\section{Reasons for presentation}

The primary reason for presentation is given in Table 1 . The largest single group was 
Table 1 Primary reason for presentation

\begin{tabular}{lr}
\hline Trauma: & \\
Open wound & 20 \\
Closed injury & 11 \\
Infective complications: & \\
Cellulitis & 13 \\
Soft tissue abscess & 10 \\
Septicaemia & 2 \\
Acute hepatitis & 2 \\
Overdose & 27 \\
Withdrawal symptoms & 5 \\
Miscellaneous & 14 \\
Total & 104 \\
\hline
\end{tabular}

Table 2 Attendance and disposal

\begin{tabular}{lr}
\hline Discharged & 56 \\
Admitted & 40 \\
Self-discharged & 6 \\
Died & 2 \\
\hline
\end{tabular}

related to trauma and in $65 \%$ of these attendances were as a result of an open wound. A total of 26 attendances were due to overdose from intravenous administration of opiates and there was one case of oral benzodiazepine overdose. Two patients were admitted with acute hepatitis, one of whom was diagnosed as having hepatitis B but the second had no serological markers of hepatitis A or B.

\section{Disposal}

A total of $37 \%$ of all patient attendances required hospital admission (Table 2). Two patients died in the accident and emergency department from hypoxic cardiac arrest secondary to heroin overdose, having arrived in a moribund state. The majority of admissions were to the poisons unit as a result of deliberate or accidental overdose and $33 \%$ of admissions were to a surgical unit (Table 3 ).

Table 3 Admitting unit

\begin{tabular}{ll}
\hline Poisons Unit & 21 \\
Surgical: & \\
General & 6 \\
Cardiothoracic & 3 \\
Neurosurgical & 2 \\
Orthopaedic & 2 \\
Oral & 1 \\
Medical & 3 \\
I.D. Unit & 2 \\
\hline
\end{tabular}

\section{Hepatitis B status}

A total of 54 patients $(58 \%)$ had radioimmunoassay performed for markers of hepatitis B virus (Table 4). Recent infection implies a resolving infection of 2-3 months' duration. 
Table 4 Hepatitis B status



There has been a dramatic increase in the number of parenteral drug abusers attending the Accident and Emergency Department of Edinburgh Royal Infirmary (McGowan $e$ e $a l ., 1984)$ and this prospective study confirms a continuing problem.

The apparent fluctuation in attendance may reflect the local availability of opiates and it is interesting to note that $58 \%$ of admissions due to intravenous opiate overdos occurred during August, including the two related deaths.

Of particular concern was the fact that the largest single group attending was af result of trauma and substantially more than half had open wounds, including patients who had been stabbed. There is therefore a definite risk to accident atho emergency staff from infection with various transmissible agents (Seef, 1975; Saslow $e$ e. al., 1975).

Infective complications of parenteral drug abuse are well described (Hussey $\&$ Katz $\overrightarrow{\vec{H}}$ 1950; Hau \& Kallick, 1980; Fullarton, 1983). In accordance with Webb \& Thadepallo (1979) we found that soft tissue infections are the commonest type of infection encountered in the accident and emergency department.

McGowan et al. (1984) reported on a frequent presentation of patients with apparen 'withdrawal symptoms' but this was not a common form of presentation during this. study. Again, this may be related to local availability of opiates.

The increase in attendances of intravenous drug abusers not only has implications foê the accident and emergency department but also for other hospital units, as greater than one-third of patient attendances resulted in admission.

A total of $5.6 \%$ of patients whose serum was assayed were HBsAg-positive and previous studies have reported a wide range, between 1.2\% (Cherubin et al., 1972) and $39 \%$ (Anderson et al., 1973). In this area, it would appear that the risk of transmission? of hepatitis B virus from intravenous drug abusers, as a group, to accident an emergency staff is relatively low.

In $87 \%$ of cases, there was evidence of past or ongoing infection with hepatitis B virus? which is higher than previously reported (Arnold, 1981). This indicates a high rate of transmission within the population of intravenous drug abusers in this area. It mase suggest that those patients who attend the accident and emergency department injecto 
themselves more frequently or have been parenteral drug abusers for a longer period of time, and may also imply that there is a high level of needle sharing.

Parenteral drug abusers present considerable problems in terms of their unpredictable behaviour and poor compliance. They will continue to use the accident and emergency department as a primary source of referral and it is therefore essential that junior casualty officers and nursing staff are made aware of the particular problems involved in the management of these patients.

\section{ACKNOWLEDGEMENTS}

We thank Dr J. Peutherer, Department of Virology, University of Edinburgh for his invaluable assistance; Dr K. Little for permission to study and report on patients under his care; and Miss Margaret Morgan for preparing the manuscript.

\section{REFERENCES}

Andersen B. M., Ellekjaer E. F. \& Ulstrup J. C. (1973) Hepatitis in non hospitalized drug addicts. Scandinavian fournal of Infectious Diseases 5, 91-6.

Arnold W. (1981) The significance of hepatitis B infection in drug addicts. In Proceedings of the European Symposium on Hepatitis B pp. 75-82. Merck Sharp \& Dohme International.

Cherubin C. E., Kane S., Weinberger D. R., Wolfe E. \& McGinn T. (1972) Persistence of transaminase abnormalities in former drug addicts. Annals of Internal Medicine 76, 385-9.

Fullarton G. M. (1983) Soft tissue infections in drug abusers presenting to an accident and emergency department. Health Bulletin (Edinburgh) 39, 296-9.

Hau T. \& Kallick C. A. (1980) Surgical infections in drug addicts. World fournal of Surgery 4, 403-13.

Hussey H. H. \& Katz S. (1950) Infections resulting from narcotic addiction. American fournal of Medicine 9 , 186-93.

McGowan A., Steedman D. J., Schofield T. C. \& Robertson C. E. (1984) Parenteral drug misuse and the accident and emergency department. Health Bulletin (Edinburgh) 42, 252-7.

Saslow A. R., Hamman W. M. \& Ryckeck R. R. (1975) 'Hippie Hepatitis': an epidemiological investigation conducted within a population of 'street people'. American fournal of Epidemiology 101, 211-19.

Seeff L. B. (1975) Hepatitis in the drug abuser. Medical Clinics of North America 59, 843-8.

Webb D. \& Thadepalli H. (1979) Skin and soft tissue polymicrobial infections from intravenous abuse of drugs. Western fournal of Medicine 130, 200-04. 